\title{
Differences in recruitment order of motor units in phasic and tonic flexion reflex in 'spinal man'
}

\author{
LENNART GRIMBY AND JAN HANNERZ
}

From the Department of Neurology, Karolinska Hospital, Stockholm, Sweden

SUMMARY The recruitment order of motoneurones in muscle contractions has been held to beo largely constant and determined by the size of the cell. However, as shown in a previous investigation $\overline{\bar{\rho}}$. using electromyographic techniques, the order in which different motor units are activated during ${ }^{\Phi}$ voluntary muscle contractions changes in normal human subjects on shifts from phasic to tonic contraction. In order to investigate these two types of activity also in cases in which the cerebral $\vec{\circ}$ influence on the motoneurone pool is blocked, an analysis was made of the recruitment order inphasic and tonic flexion reflexes in 10 patients with total interruption of the spinal cord. The follow- $-\vec{\omega}$ ing four principles were found to apply and presumed to be generally valid for the isolated human 5 spinal cord: (1) in the phasic exteroceptive reflex, the order of recruitment varies despite applicationz of a standardized stimulus; (2) in the tonic reflex, the first unit to be recruited is usually the same even with widely different types of stimuli; (3) a shift from phasic to tonic reflex activation may resultiv in considerable changes in recruitment order; (4) after facilitation by a subliminal long-lastiōgg stimulus, the first unit to be recruited in the phasic reflex is also the first to be recruited in the tontic reflex. It is suggested that a tonic influence on the motoneurone pool is required for the presupposed constancy of the recruitment order.

The mechanisms governing the recruitment of individual motoneurones have been extensively studied in animal experiments. Tonic neurones mediate sustained activity, whereas phasic neurones are active only for very brief periods (Denny-Brown, 1929; Granit, Phillips, Skoglund, and Steg, 1957). The motoneurones of the tonic units are considered to be smaller than those of the phasic units (Granit et al., 1957). Since small cells have a larger input resistance than large cells (Kernell, 1966; Burke, 1968a), the tonic neurones are more easily activated than the phasic ones except if the number of active synapses is far larger or if they are more effectively located for phasic than for tonic cells, thus compensating for the low input resistance of the phasic neurones. Most investigators have not found any significant deviations from the general rule that small motoneurones are recruited before large ones (Henneman, Somjen, and Carpenter, 1965a, b; Somjen, Carpenter, and Henneman, 1965; Burke, $1968 \mathrm{a}$, b). It has even been suggested that the

${ }^{1}$ This investigation was partially supported by research grants from Karolinska Institutet and from the Swedish Multiple Sclerosis Society, Stockholm. recruitment order is determined by the input resitance, which is a function of cell size, and thata particular cell receives the same proportion of the total input from each source of activation (Henneman et al., 1965b). However, results that do not fit in with this concept have also been reported $\bar{D}$ thus, phasic motoneurones when activated througlo the pyramidal tract may be recruited more readil 8 than the tonic cells (Preston and Whitlock, 1963 Sasaki and Tanaka, 1964; Clough, Kernell, an Phillips, 1968).

In electromyographic recordings single units cap be identified with full certainty by the characteristis and constant shape of their potentials (Smith, 1934 Grimby and Hannerz, 1968), and with the aid of this technique it is now possible to study the functiona properties of single motoneurones in man as unequivocally as in recordings from single nerve fibres in animal experiments.

In a previous investigation (Grimby and Hannerz 1968) we showed that in normal human subjects the order of recruitment of the single units on voluntar muscle contraction differs on phasic and tonio contraction and is influenced by proprioceptives afferent impulses. Since changes in the normat 
threshold relationships between phasic and tonic motoneurones and in the proprioceptive afferent activity are essential factors in states of spasticity and rigidity, we have considered it pertinent to perform a similar analysis of the recruitment of motor units in patients with different types of motor disorders as well.

The aim of the present investigation, the first in a series of such analyses, has been to compare the order of recruitment in phasic and tonic reflexes in patients with total interruption of the spinal cord and consequent loss of cerebral influence on the motoneurone pool. The investigation is based on studies of the exteroceptive flexor reflex; the proprioceptive extensor reflex is not equally well suited for experiments of this type, since the recording electrodes are apt to be displaced in the tonic reflex and the units are synchronized in the phasic reflex.

\section{MATERIAL AND METHODS}

The subjects of this investigation were 10 patients with spinal lesions causing total loss of voluntary movement as well as total sensory loss below the level of injury. Details about the patients are given in the Table.

TABLE

CLINICAL DETAILS

\begin{tabular}{|c|c|c|c|c|c|}
\hline \multicolumn{3}{|c|}{ Patient } & \multicolumn{3}{|c|}{ Injury } \\
\hline No. & Sex & $\begin{array}{c}\text { Age } \\
(y r)\end{array}$ & Type & Level & Duration \\
\hline 1 & $\mathbf{M}$ & 24 & Traumatic & T 12 & 4 wk \\
\hline 2 & $\mathbf{M}$ & 26 & Traumatic & C 6 & $5 \mathrm{yr}$ \\
\hline 3 & $\mathbf{M}$ & 57 & Traumatic & T 12 & $26 \mathrm{yr}$ \\
\hline 4 & $\mathbf{M}$ & 22 & Myelitis & $T$ & 1 wk \\
\hline 5 & $\mathrm{~F}$ & 36 & Myelitis & $\mathbf{T}$ & 2 wk \\
\hline 6 & $\mathbf{M}$ & 17 & Traumatic & C 5 & $1 \mathrm{yr}$ \\
\hline 7 & $\mathbf{M}$ & 19 & Traumatic & C 5 & $2 \mathrm{yr}$ \\
\hline 8 & $\mathrm{~F}$ & 22 & Traumatic & T 8 & $2 \mathrm{mth}$ \\
\hline 9 & $\mathbf{M}$ & 15 & Traumatic & T 3 & $10 \mathrm{yr}$ \\
\hline 10 & $\mathbf{M}$ & 26 & Traumatic & C 6 & $4 \mathrm{yr}$ \\
\hline
\end{tabular}

Most of the patients were examined on several occasions at intervals of up to some months.

In the experiments the tibialis anterior muscle was tested. The recording electrodes were placed proximally near the tibia to exclude recordings of potentials set up from other muscles, and comparatively near the muscle surface to avoid displacements of the recording electrodes. Histochemical analysis of the muscle area under study revealed a mixture of pale muscle fibres rich in myofibrillar adenosine triphosphatase and of red fibres with a smaller supply of this enzyme. Since phasic units can be presumed to consist exclusively of pale muscle cells and tonic units exclusively of red cells (Kugelberg and Edström, 1968; Edström and Kugelberg, 1968), both types of unit were thus present within the muscle area.
The motor unit potentials were recorded with bipolar needle electrodes (Disa no. 9013K0802) which have previously been shown to have a selectivity neither too high nor too low for experiments of this type (Ashworth, Grimby, and Kugelberg, 1967). To be able to record the activity of a greater number of motor units, two electrodes were sometimes used in simultaneous recordings. The potentials were amplified and displayed on two oscilloscopes - namely, a standard oscilloscope with continuous sweep and a Tektronix storage oscilloscope no. 564 which was triggered by the stimulus or by the first positive deflection of the first potential in each sequence. All experiments were recorded on tape and the results obtained were confirmed by repeated playbacks and by film recordings of the principal parts.

The technique of eliciting the phasic flexion reflex was the same as used by Ashworth et al. (1967) in studies on normal subjects. Electric stimuli were applied to the plantar surface of the foot by means of a pair of needles inserted into the skin. The stimulus consisted of a series of shocks delivered over a period of $10 \mathrm{msec}$ and of a single-shock duration of $1 \mathrm{msec}$ at a frequency of $500 / \mathrm{sec}$. Subjects with intact sensibility experienced the stimulus as a brief intense needle prick.

A potential, to be identified as deriving from a given unit, had to be of a characteristic size and shape and remain unchanged during repeated activations. A second potential was defined as belonging to a second unit only if it were set up alternating with the first potential. A prerequisite for a third potential to be identified as deriving from a third unit was also that its size and shape excluded its being built up of potentials number one and two. And so forth. By the criteria thus established it could be ascertained that the potentials evoked represented functionally separate units in the muscle. It is true that it cannot be ruled out that some of the potentials might be derived from synchronized motor units, but this does not invalidate the conclusions drawn.

\section{RESULTS}

PHASIC REFLEX In the patients under study the reflex threshold varied widely in the course of each experiment, the threshold reflexes having latencies ranging from 100 to $400 \mathrm{msec}$ and durations from 5 to 50 msec.

By gradually adjusting the stimulus strength to the fluctuations in reflex threshold, a series of phasic reflexes, each deriving from one up to four identifiable units, could be induced in all experiments performed. In such a series, the single-unit reflexes were set up now by one, now by another of the units in a group comprising at least three units. In the multi-unit reflexes, the units were recruited in series, and this provided an additional test that different units were actually involved in the reflexes (Figs. 1, $2 \mathrm{~A}$, and $3 \mathrm{~A}$ ).

In one experiment followed up for one hour (case 1, Fig. 1) no less than six different units alternated in the phasic threshold reflex, five of 



FIG. 1. Variability of recruitment order in phasic nociceptive threshold reflexes. In the eight reflexes six different units alternate, five of which occur in single-unit reflexes. Time bar $10 \mathrm{msec}$.

which were recruited in single-unit reflexes, whereas one was active only in reflexes set up by two units. and Jan Hannerz
If the experiment could have been pursued still
longer, additional units would very likely have been activated. To achieve recordings of six different units by the technique employed, a normal subjecten had to apply about one-fourth of his maximatô contraction strength in a tonic voluntary con- 0 traction (Hannerz, in preparation). In such a? contraction the smaller and weaker units are the first to be recruited (Denny-Brown and Pennybacker, 1938), and the total number of units within the recording range of the electrode should be less $\overrightarrow{\vec{F}}$ than four times six. The units activated in single-unif reflexes in Fig. 1 thus represented a large proportion of the total unit population within the recordinge range of the electrodes.

Some units were recruited as number one unif only in reflexes of comparatively long latency, whereas other units dominated the activity only in $\overrightarrow{0}$ reflexes of fairly short latency (Figs. $2 \mathrm{~A}, 3 \mathrm{~A}$ ). Thevariability in recruitment order was smaller when high stimulus strength was required to elicit the reflex than when a weak stimulus was sufficient. In several experiments occasional spontaneous activitytu set up by units varying from spasm to spasm was observed (Fig. 3 B). In one experiment the sameir unit alternated as first unit both in the phasic reffex and in the spontaneous spasm (cf. Fig. $3 \mathrm{~A}$ and $\mathrm{B}$ )윽 The order of recruitment in the phasic reflex thus largely dependent on the level of excitability 9 ino the motoneurone pool at the moment of stimulationf and varied with spontaneous fluctuations in excitability and not with unintentional variations $\$ \hat{C}$ the afferent volley.

To induce a reflex set up by a single unit it was often necessary to adjust the stimulus strength very? carefully. Even a minute increase in stimulus strength sufficed to yield a synchronous burst of several units (Fig. 2 B, upper record). The first unit recruited in a phasic reflex thus displayed very smal[ differences in threshold.

These results are not compatible with previous? hypotheses, based on studies of the reflex activity in animal experiments, to the effect that the order of recruitment should be mainly dependent on the size of the cells and consequently constant (Henneman et al., 1965a, b; Somjen et al., 1965). Significan? variations in the order of recruitment of motoneurones have earlier been observed only during voluntary activity in man (Seyffarth, 1940; Ashworth et al.ફु 1967; Grimby and Hannerz, 1968).

TONIC REFLEX By gently stroking a blunt needle along the sole of the patient's foot the investigator could after some training induce a smooth sustainedy contraction of the tibialis anterior muscle and regulate the strength of this contraction. In the 


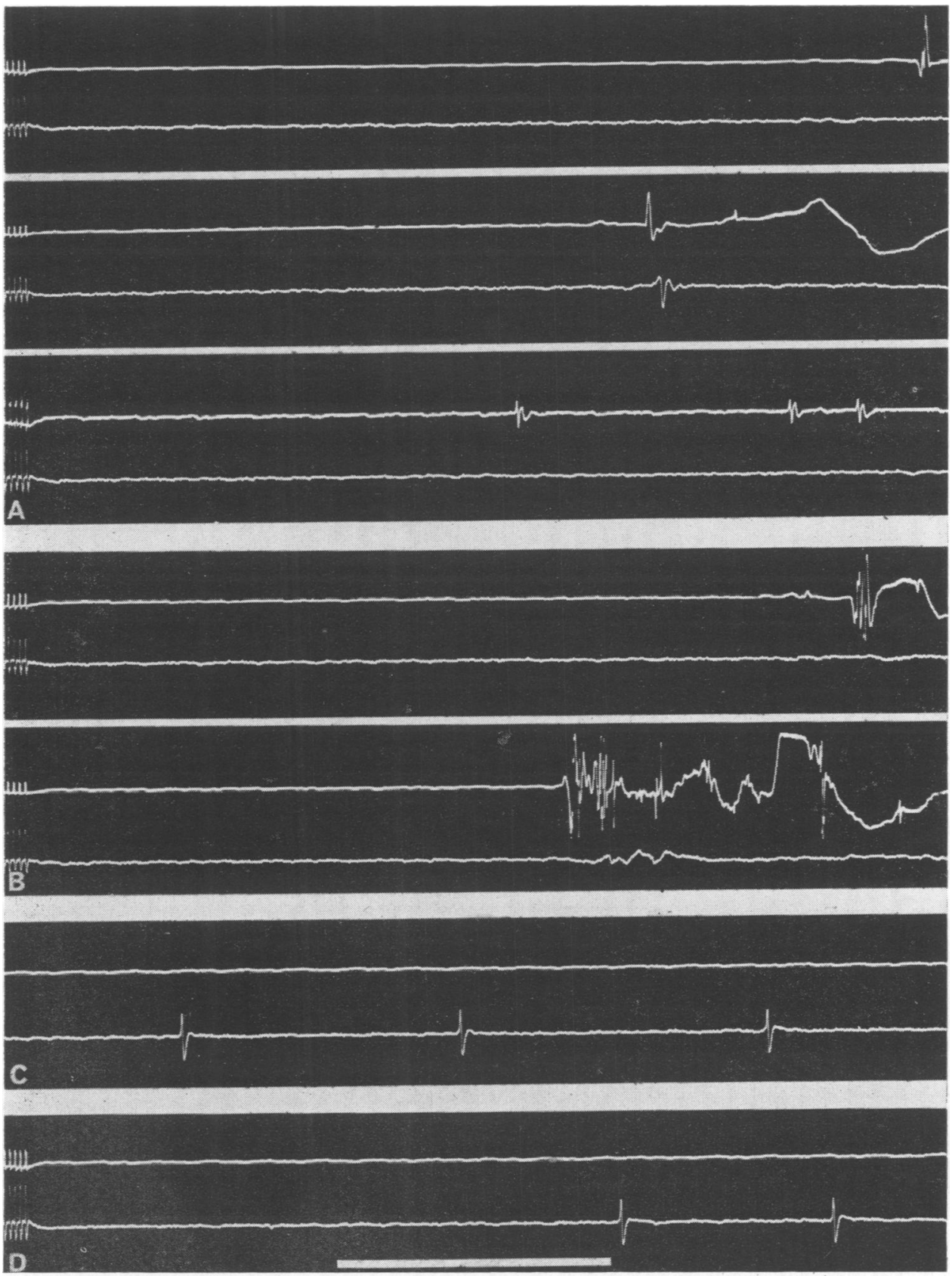

FIG. 2. Differences in recruitment order in phasic and tonic nociceptive reflexes. Two electrodes inserted at different sites in the muscle, a few cm apart (upper and lower traces in each recording). A: three phasic threshold reflexes; B, upper record: barely suprathreshold, B, lower record: submaximal, phasic reflex; $\mathrm{C}$ : tonic reflex; D: phasic reflex after nociceptive subliminal facilitation. Note difference between $\mathrm{B}$ (reflex only in upper trace) and D (reflex only in lower trace.) Time bar 100 msec. 

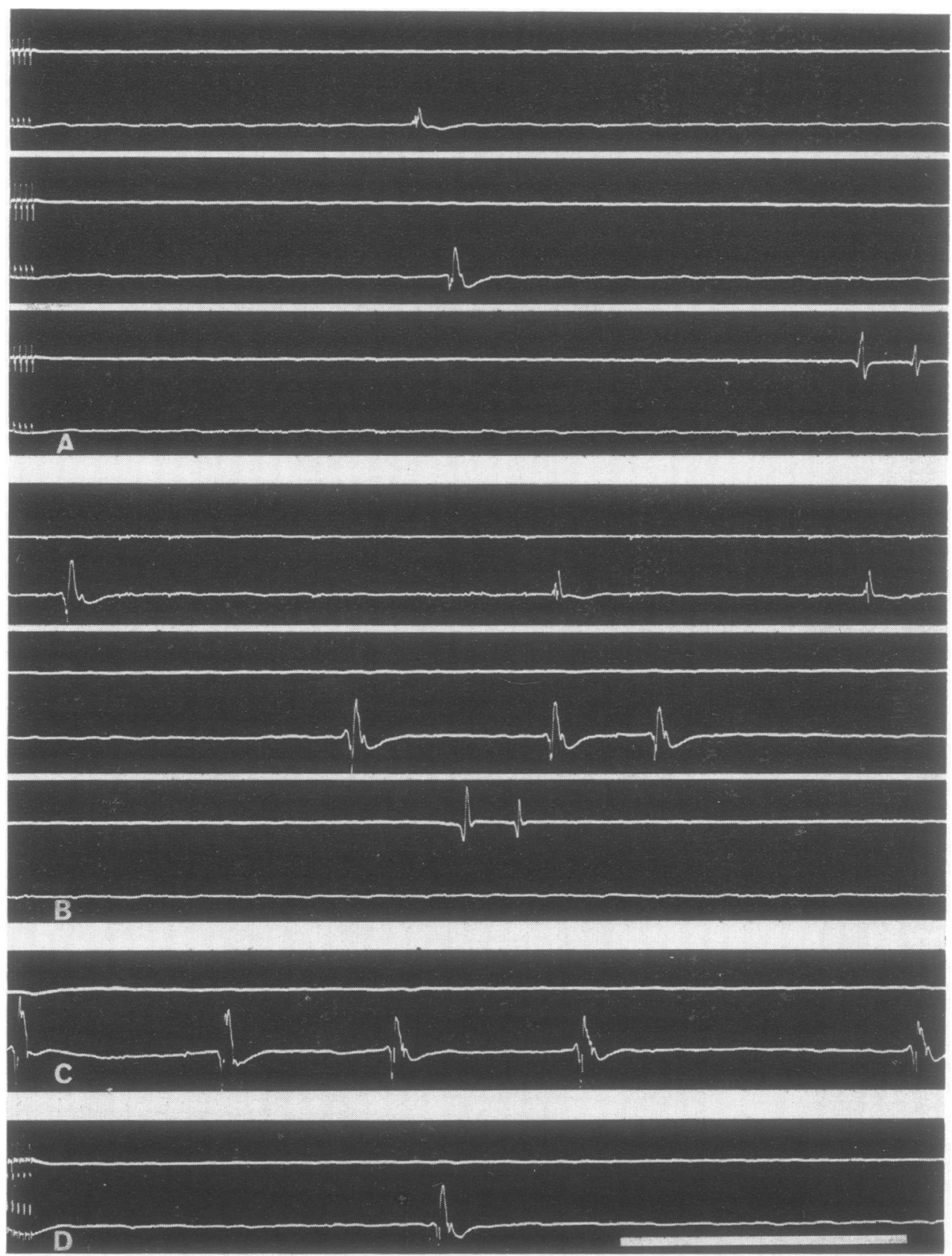

FIG. 3. Changes from variable to constant recruitment order after proprioceptive subliminal facilitation. Two electrodes inserted at different sites in the muscle, a few $\mathrm{cm}$ apart (upper and lower traces in each recording). A: three phasic nociceptive threshold reflexes; B: three brief spontaneous spinal spasms; C: tonic proprioceptive reflex during gradually decreasing muscle stretch; during the initial, higher degree of stretch the potential is slightly altered but resumes its original shape as soon as the stretch is reduced. D: phasic nociceptive reflex set up after proprioceptive facilitation. Note high frequency $(16 / \mathrm{sec})$ attained by the unit recruited in the tonic reflex $(\mathrm{C})$ in the absence of activation of other units, whereas several units alternate in the phasic reflexes. Time bar $100 \mathrm{msec}$. 
chronic cases this tonic reflex was always as readily elicitable as the phasic reflex, but in the acute cases a smooth sustained contraction could only occasionally be induced, and then with considerable difficulty. A follow-up of some cases is in progress to try to find out if some change in the relationships of the phasic and tonic nociceptive reflexes might arise when a spinal cord lesion passes from the acute to the chronic stage.

In contrast to the phasic reflex activity, the first unit to be recruited in tonic reflex activity was usually the same in repeated activations (Fig. $2 \mathrm{C}$ ). The stimulus strength could be considerably increased and the discharge might attain a frequency of about $10 / \mathrm{sec}$ before the second unit started to respond. The thresholds of the first two units to be recruited thus differed far more widely in the tonic than in the phasic reflex.

In one experiment in which a tonic reflex could easily he evoked (case 2, Fig. 2 C), a number of different modes of excitation were tested-namely, blunt needle, sharp needle, weak repeated electric skin stimuli of the type yielding a phasic reflex, pressure applied to deep structures of the foot, exaggerated stretch of the toe joints, cold $\left(0^{\circ} \mathrm{C}\right)$, warmth $\left(50^{\circ} \mathrm{C}\right)$, and mechanical vibration applied to soft and bony structures. With all these types of stimuli, one and the same unit was invariably recruited first in the reflex.

In cases of particularly strong spasticity, a tonic reflex activity could be maintained by continuous stretch of the tendon of the tibialis anterior. In order to stretch the tendon, the investigator had to touch the patient's foot. Small movements of the electrodes occurring during the stretch might also give rise to afferent impulses. However, these two factors alone did not cause a maintained discharge. On release of stretch the activity was immediately abolished under otherwise identical conditions of facilitation, and it was thus interpreted as being evoked by a tonic proprioceptive reflex. Unfortunately, it was not possible to avoid displacements of the recording electrodes during the stretch of the tendon, but in several experiments with one patient the amount of stretch needed to set up the reflex was so small that the potential remained essentially unchanged.

Also when a tonic reflex was thus maintained by a proprioceptive stimulus, the same unit was invariably the first to be recruited in a series of iterative activations, and the discharge might attain a frequency exceeding 10/sec (Fig. 2 C) before the second unit started firing. The first unit to be activated in the tonic exteroceptive reflex was also the first to be recruited in the tonic proprioceptive reflex.
Whereas in the phasic reflex the recruitment order of the units varied despite application of a standardized stimulus, one and the same unit was thus always the first to be activated in the tonic reflex, even though widely different types of stimuli were applied.

The large and consistent difference in thresholds observed between the first and second units recruited in the tonic exteroceptive and proprioceptive reflexes in spinal man is in accord with findings reported from investigations of voluntary tonic contractions (Seyffarth, 1940; Ashworth et al., 1967; Grimby and Hannerz, 1968). The constancy of the number one unit in the tonic reflex even with widely different types of stimuli also agrees with results obtained in studies of the recruitment order in normal man (Ashworth et al., 1967) and in decerebrate cat (Henneman et al., 1965a, b; Burke, 1968a, b).

DIFFERENCES IN PHASIC AND TONIC RECRUITMENT In some experiments, a unit never recruited even in strong phasic reflexes might become predominant in the tonic reflex (cf. Fig. 2 B and C). In other experiments, one of the units alternating as number one unit in the phasic reflex might become the first to be recruited in the tonic reflex (cf. Fig. $3 \mathrm{~B}$ and C), but also in these recordings there were periods in which the phasic and tonic recruitment order differed widely.

Significant changes in the recruitment could thus be produced in all subjects on shifts from phasic to tonic reflex contraction. Since the material under study includes subjects with recent injuries as well as those with lesions of very long standing, these effects should be attributable to some mode of reaction of the isolated human spinal cord.

Changes in the recruitment order of motoneurones on shifts from phasic to tonic reflex contraction have not previously been described. Evidence has however been presented which indicates that, even though tonic units are the first to be recruited when the activity is mediated through Group I a afferents, phasic units may be the first to be recruited when it is mediated through the pyramidal tract (Preston and Whitlock, 1963; Sasaki and Tanaka, 1964).

PHASIC REFLEX: EFFECTS OF SUBLIMINAL FACILITATION When a long-lasting subliminal stimulus was delivered to the sole of the foot before the electric stimulus was applied, the strength of this latter stimulus could be reduced by about half. The spontaneous fluctuations in reflex threshold during an experiment were, however, so large that nonfacilitated phasic reflexes might be evoked by a stimulus even weaker than that yielding a facilitated reflex. 
The adequate level of subliminal facilitation was most readily attained by application of an initial barely suprathreshold stimulus, gradually reducing its strength. The facilitation could, however, be induced without any preceding activation of units, but in such cases the experimenter had no means of assessing the level attained when he applied the electric stimulus. The facilitation might be sustained for $15 \mathrm{sec}$ after the facilitating stimulus had been withdrawn.

During exteroceptive subliminal facilitation, the order of recruitment in the phasic reflex was more in accordance with that in the tonic reflex. Thus, even in recordings in which the two reflexes initially displayed wide differences in recruitment order (cf. Fig 2 B and C), the first unit to be activated in the facilitated phasic reflex became identical with that in the tonic reflex (cf. Fig. $2 \mathrm{C}$ and D); further, the threshold difference between the first two units to be recruited after the facilitation was found to be as wide as in the tonic reflex, and reflexes deriving from a single unit could now easily be evoked.

A similar subliminal state of facilitation could also be achieved by stretch of the tendon of the tibialis anterior muscle. As mentioned above, the stretch unfortunately displaced the recording electrodes, but in repeated experiments with one patient the amount of stretch needed to elicit the reflex was so small that the shape of the potentials remained essentially constant. In these tests, the first unit to be recruited in the phasic reflex became identical with that in the tonic reflex when the muscle was subjected to stretch (Fig. $3 \mathrm{C}$ and $\mathrm{D}$ ). When the tendon was released the original sequence of recruitment was immediately re-established.

\section{DISCUSSION}

The results obtained in the present investigation may be summed up as follows: (1) In the phasic exteroceptive reflex, the order of recruitment of motor units varies despite application of a standardized stimulus. (2) In the tonic reflex, the first unit to be recruited is usually the same even with widely different types of stimuli. (3) A shift from phasic to tonic reflex activation may result in considerable changes in recruitment order. (4) After facilitation by a subliminal long-lasting stimulus, the first unit to be recruited in the phasic reflex is also the first to be recruited in the tonic reflex. These differences between phasic and tonic flexion reflexes in spinal man agree with those previously shown to exist between phasic and tonic voluntary contraction in healthy man (Grimby and Hannerz, 1968).

The concept has been advanced that motor units should be recruited in a fixed sequence, indepen dently of the afferent inflow (Henneman et al.x) 1965 a, b; Ashworth et al., 1967). Our findingso suggest, however, that the afferent inflow is ant essential factor in the recruitment order but tha background excitation, facilitating the activity, may. play a more important part than the afferent volleys eliciting the activity. The reason why the significanceo of the afferent inflow has not previously beeno observed may be that earlier results were based on experiments in which a continual background excitability was apt to be maintained. In a previous investigation on normal human subjects, the recruitment order was found to be identical in tonic voluntary contraction and phasic flexion reflexactivation in no less than $80 \%$ of the experiments (Ashworth et al., 1967). But in the intact organism the motoneurone pool is easily influenced by a sus? tained cerebral activity, the effect of which on the्छు recruitment order is similar to that of a tonicer peripheral inflow (Hannerz and Grimby, 1971). Jurg earlier experiments on decerebrate cats it has betn found that out of any two ventral root fibres respond응 ing in a reflex, one and the same was always the first to be activated regardless of the way excitation (Henneman et al., 1965). In the dec8ro ebrate preparation there may however be a bae ground excitatory bias favouring tonic units (Burk $\overline{\bar{z}} \overrightarrow{\mathrm{\vartheta}}$ 1968b).

In experiments in which axonal conduction velocity (Granit et al., 1957), extracellular spike amplitude (Henneman et al., 1965a, b) or inpus resistance (Burke, 1968a, b) were taken as index of the size of the motoneurones, the excitability of the cells was found to be an inverse function of theip cell size. The hypothesis was advanced that a par $\overrightarrow{\bar{O}}$ ticular cell receives the same proportion of the tota input from each of the systems which is afferent te it, and that the input resistance which is a direct. function of cell size is the decisive factor in the recruitment pattern (Henneman et al., 1965b). Ou? finding that the recruitment order is constant in the tonic reflex fits in well with this concept, and in tonic afferent activity the smallest unit should always be the first to be activated. From our finding that the recruitment order is widely varying in the phasic reflex it is however evident that the size principle is not generally valid. With respect to the units we have recorded from in our experiments. we do not know anything about neurone size, an $\Phi$ hence we cannot draw any conclusions about the relative significance of motoneurone size and్ట background excitation in phasic activity.

The tonic neurones have been defined as cells capable of maintaining long-lasting concealed states of facilitation (Granit, 1957). The shifts in recruite 
ment order resulting on subliminal facilitation were building up gradually and sustained over long periods of time, and the units thus facilitated should be tonic. To what extent phasic neurones may have been activated in the experiments cannot however be decided from the electromyographic recordings. The functional difference between the two types of unit is mirrored in the properties of the muscle fibres. Some units consist exclusively of red fibres which are capable of long-lasting sustained activity without undue fatigue; some units, on the other hand, have exclusively pale muscle fibres with very low fatigue level (Kugelberg and Edström, 1968; Edström and Kugelberg, 1968). The red type of unit should be capable of the sustained activity that has been attributed to tonic units. The pale type of unit, on the other hand, should be capable only of brief periods of activity - that is, be phasic. The superficial, proximal portion of the tibialis anterior muscle usually studied in our experiments is composed of a mixture of red and pale muscle fibres (Fig. 4), thus presumably both of tonic and phasic units. The changes in recruitment order resulting on shifts from phasic to tonic reflex activity might, in part, have been due to phasic units being substituted by tonic units. However, the changes should also be due to threshold changes in the tonic motoneurone pool; such changes have previously been shown to occur on shifts from phasic to tonic voluntary contraction (Grimby and Hannerz, 1968).

Alpha motoneurones may be activated either directly or indirectly through the gamma loop

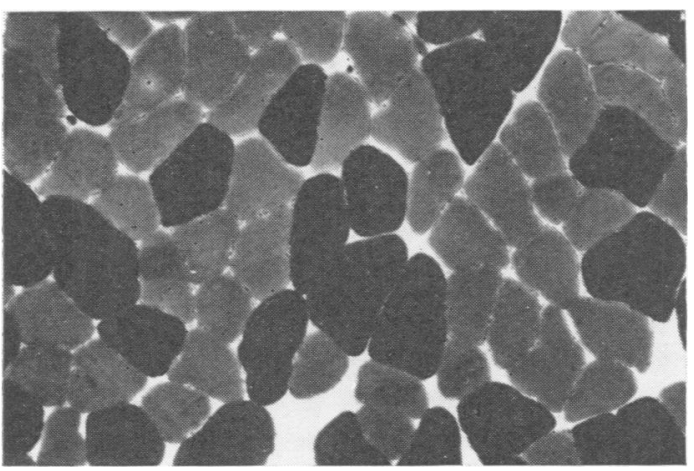

FIG. 4. Histochemical distribution of phasic and tonic units within the muscle area under study. Phasic units are composed exclusively of fibres rich in adenosine triphosphatase (dark) and tonic units exclusively of fibres with a smaller supply of this enzyme (light). Both phasic and tonic units present.
(Leksell, 1945). According to Granit (1957) the direct route of activation is predominant only in very rapid contractions, whereas in other cases facilitation through the gamma loop is decisive. As shown by us, proprioceptive afferent impulses are capable of reversing the recruitment order in the voluntary contractions of normal human subjects (Grimby and Hannerz, 1968), as well as in reflex contractions in spinal man (Fig. 3). It would be tempting to explain the constant order of recruitment prevailing in all types of tonic contractions by their being set up through the gamma loop. But Henneman and collaborators (1965a) have shown that the recruitment remains constant in the tonic extensor reflex when the gamma loop is eliminated, and this pathway cannot thus alone be responsible for the recruitment order. Whenever a facilitation occurs through the gamma loop, the effect of which on the motoneurone pool is truly tonic (Kuffler, Hunt, and Quilliam, 1951), the result should however be a recruitment pattern of a more tonic character. All tonic influences, direct as well as indirect through the gamma loop, are thus likely to participate in the building up of the tonic pattern of recruitment.

The rate of accommodation varies in different nervous structures-namely, the rate of rise of the stimulus needed for eliciting a response may differ (see Kugelberg, 1944). Accommodation does not however play any important part in motoneurone activity (Bradley and Somjen, 1961), and the different recruitment order in phasic and tonic reflexes should thus hardly be explicable in terms of accommodation.

Synchronous impulses set up in the pyramidal tract by electric shock stimuiation of the motor cortex may have an inhibitory effect on tonic motoneurones (Preston and Whitlock, 1963). The impulse volley resulting from a sudden nociceptive electric skin stimulus does not seem to have a similar inhibitory effect since the facilitated phasic reflex becomes identical with the tonic reflex.

Alpha motoneurone activity gives rise to complex feed-back effects on the motoneurone pool. Such effects should affect the first unit less than the subsequent units, and phasic reflexes less than tonic, and may contribute to the difference between phasic and tonic recruitment order. But in the nociceptive reflex gamma motoneurones of lower threshold than the alpha neurones are activated (Eldred and Hagbarth, 1954), and on slow activation the proprioceptive facilitation should thus already have been initiated before any feed-back effects from alpha activity could set in. And so we are back at the gamma loop. Further studies are in progress to elucidate the functional role of this pathway. 


\section{REFERENCES}

Ashworth, B., Grimby, L., and Kugelberg, E. (1967). Comparison of voluntary and reflex activation of motor units. J. Neurol. Neurosurg. Psychiat., 30, 9198.

Bradley, K., and Somjen, G. G. (1961). Accommodation in motoneurones of the rat and the cat. J. Physiol. (Lond.), 156, 75-92.

Burke, R. E. (1968a). Group Ia synaptic input to fast and slow twitch motor units of cat triceps surae. $J$. Physiol. (Lond.), 196, 605-630.

Burke, R. E. (1968b). Firing patterns of gastrocnemius motor units in the decerebrate cat. J. Physiol. (Lond.), 196, 631-654.

Clough, J. F. M., Kernell, D., and Phillips, C. G. (1968). The distribution of monosynaptic excitation from the pyramidal tract and from primary spindle afferents to motoneurones of the baboon's hand and forearm. J. Physiol. (Lond.), 198, 145-166.

Denny-Brown, D. E. (1929). On the nature of postural reflexes. Proc. roy. Soc. $B, 104,252-301$.

Denny-Brown, D., and Pennybacker, J. B. (1938). Fibrillation and fasciculation in voluntary muscle. Brain, 61, 311-334.

Edström, L., and Kugelberg, E. (1968). Histochemical composition, distribution of fibres and fatiguability of single motor units. J. Neurol. Neurosurg. Psychiat., 31, 424-433.

Eldred, E., and Hagbarth, K. E. (1954). Facilitation and inhibition of gamma efferents by stimulation of certain skin areas. J. Neurophysiol., 17, 59-65.

Granit, R. (1957). Systems for control of movement. 1er congr. internat. sci. neurol. Bruxelles. pp. 63-80.

Granit, R., Phillips, C. G., Skoglund, S., and Steg, G. (1957). Differentiation of tonic from phasic alpha ventral horn cells by stretch, pinna and crossed extensor reflexes. J. Neurophysiol., 20, 470-481.

Grimby, L., and Hannerz, J. (1968). Recruitment order of motor units on voluntary contraction: changes induced by proprioceptive afferent activity. J. Neurol. Neurosurg. Psychiat., 31, 565-573.
Hannerz, J., and Grimby, L. (1971). Recruitment order of motor units in the flexion reflex in man: variations induced by changes in the subject's attention and expectancy. To be published.

Henneman, E., Somjen, G., and Carpenter, D. O. (1965a). Functional significance of cell size in spinal motoneurons. J. Neurophysiol., 28, 560-580.

Henneman, E., Somjen, G., and Carpenter, D. O. (1965b). Excitability and inhibitibility of motoneurons of different sizes. J. Neurophysiol., 28, 599-620.

Kernell, D. (1966). Input resistance, electrical excitability and size of ventral horn cells in cat spinal cord. Science, 152, 1637-1639.

Kuffler, S. W., Hunt, C. C., and Quilliam, J. P. (1951). Function of medullated small-nerve fibres in mammalian ventral roots: efferent muscle spindle innervation. J. Neurophysiol., 14, 29-54.

Kugelberg, E. (1944). Accommodation in human nerves. Acta physiol. scand., 8, suppl. XXIV. 1-105.

Kugelberg, E., and Edström, L. (1968). Differential histochemical effects of muscle contractions on phosphorylase and glycogen in various types of fibres: relation to fatigue. J. Neurol. Neurosurg. Psychiat. 31, 415-423.

Leksell, L. (1945). The action potential and excitatory effects of the small ventral root fibres to skeletal muscle. Acta physiol. scand., 10, Suppl. 31, pp. 1-84.

Preston, J. B., and Whitlock, D. G. (1963). A comparison of motor cortex effects on slow and fast muscle in- $C$ nervations in the monkey. Exp. Neurol., 7, 327-341.

Sasaki, K., and Tanaka, T. (1964). Phasic and tonic inne ${ }^{\circ}$ vation of spinal alpha motoneurons from uppe $\mathrm{N}$ brain centers. Jap. J. Physiol., 14, 56-66.

Seyffarth, H. (1940). The Behavior of Motor Units in Volumi tary Contraction. Dybwad: Oslo.

Smith, O. C. (1934). Action potentials from single moto units in voluntary contraction. Amer. J. Physiolo 108, 629-638.

Somjen, G., Carpenter, D. O., and Henneman, E. (1965) Responses of motoneurons of different sizes to grade $\Phi$ stimulation of supraspinal centers of the braints J. Neurophysiol., 28, 958-965. 